\title{
Effects of Nutrient Composition on Yield and Quality of Mushroom in Lentinula edodes Cultivation Using Softwood Sawdust*1
}

\author{
Ji Young Jung*2, Seong-Cheol Hong*2, Danny Lee Rinker*3, \\ Myung Suk Choi*2, Byung Hyun Lee*4, and Jae-Kyung Yang*2†
}

\begin{abstract}
This study was performed to evaluate the efficiency of using softwood as the sawdust medium for Lentinula edodes cultivation, effect of nutrient on the mycelial growth, spawning, the mushroom yield, and quality. The nitrogen nutrition significantly enhanced the mycelial growth of $L$. edodes. The glutamic acid in the L. leptolepis and P. koraiensis, and asparagine in the $P$. densiflora were appeared to slight increase in the mycelial growth. The vegetable oil showed very effective on the mycelial growth in the $P$. koraiensis sawdust medium. Carbon/nitrogen ratio of all the test was reduced after mycelial growth. The mycelial growth was exclusively dependent on reduction of carbon. The mushroom yield $(32.7 \%)$ of the $P$. densiflora sawdust medium (carbon source: $3 \%$ active carbon, nitrogen source: $0.4 \%$ asparagines) was the best in mushroom production of $L$. edodes, followed by the $Q$. variabilis sawdust (35.4\%) of the control medium. The diameter of mushroom cap was obtained from the $P$. densiflora sawdust (carbon source: $3 \%$ sucrose, nitrogen source: $0.4 \%$ potassium nitrate) and P. koraiensis sawdust (carbon source: $3 \%$ sucrose, nitrogen source: $0.4 \%$ potassium nitrate), and the P. koraiensis sawdust (carbon source: $3 \%$ xylose, nitrogen source: $0.4 \%$ glutamic acid, supplement: $0.05 \%$ amino acid), with values $71.5 \mathrm{~mm}, 71.5 \mathrm{~mm}$ and $72.1 \mathrm{~mm}$, respectively. In the polypropylene bag cultivation, the weight losses of the block medium gradually increased for 80 days in the dark $(13.8 \sim 16.8 \%)$ and then became stable in the range of $20.7 \sim 25.8 \%$.
\end{abstract}

Keywords : Lentinula edodes, mycelial, Quercus variabilis, Larix leptolepis, Pinus densiflora, Pinus koraiensis, polypropylene bag, cultivation, mushroom yield

\section{INTRODUCTION}

Mushrooms are known for their nutritional and medicinal value (Breene, 1990) and for containing a variety of bioactive compounds. Lentinula edodes (Shiitake), which is the second

*1 Received on June 21, 2009; accepted on December 10, 2009

*2 Division of Environmental Forest Science and Institute of Agriculture \& Life Science, Gyeongsang National University, Jinju 660-701, Korea

*3 Department of Plant Agriculture, University of Guelph, Vineland Station, Ontario, Canada LOR 2EO

*4 Division of Applied Life Science (BK21), Gyeongsang National University, Jinju 660-701, Korea

† Corresponding author : Jae-Kyung Yang (e-mail: jkyang@gnu.ac.kr) 
most popular edible mushrooms worldwide dueto its delicious flavour, great nutritional value and immunity-enhancing components (Jong and Nirmingham, 1993), belongs in the group of white rot basidiomycetes.

L. edodes mushroom is important in Asian countries including China, Japan, Taiwan, and Korea. This is attributed to its nutritional value and the possibility of its medical application (Jong and Nirmingham, 1993). In Korea, the $L$. edodes mushroom is mostly produced by $\log$ and sawdust cultivation. The cultivation of $L$. edodes in Korea has increased annually since the early 1970s. In 2000, the yields of dried and fresh L. edodes mushrooms were 2,278 tones and 17,454 tones, respectively, with the yield of dried and fresh $L$. edodes mushrooms increasing $10 \%$ and $3 \%$, respectively in 2001 .

Logs of broad-leaved trees have been used for cultivating some edible mushrooms. For example, Luo (1989) and Quimio et al. (1990) utilized the logs of oak trees to cultivate Auricularia in China and the Philippines. A similar work, the cultivation of $L$. edodes using oak family trees, was reported in the literature by Kuo and Kuo (1983), Singer and Harris (1987) and Miles and Chang (1997). These studies were embarked upon in order to evaluate the cultivability of L. subnuduson logs of selected Nigerian hardwoods and the effects of chemical treatments of the logs on fructification. The $L$. edodes mushrooms are cultivated on natural logs or sterilized sawdust. Recently, instead of $\log$ cultivation, which requires a long term to form fruiting bodies, a method of sawdust-based cultivation has been gradually extended. The cultivation of $L$. edodes on sawdust medium has become more popular in recent years than on $\operatorname{logs}$ in Korea. In Korea in 1995, cultivation techniques using the sawdust succeeded and these cultivation techniques were transmitted to commercial mushroom farms. Most of the culti- vation process and processing of lumber resources can be mechanized extensively. Because the method of the sawdust cultivation is conducted under controlled temperature and humidity conditions inside the cultivation rooms, it has some advantages. For example, the yield of fruiting bodies is almost independent of climatic conditions throughout the year. Simply due to the mechanization of every process of cultivation, the cultivation period is shortened to one-third or one-sixth of that of the log cultivation. A shortage of the logs occurred and sawdust of the commonly used oak trees became limited, and their purchase price increased with time because of the increase of mushroom farming. Softwood species have been investigated for the cultivation of $L$. edodes but the $L$. edodes mushroom has grown poorly on the softwood such as $P$. densiflora, where both the fruit body production and quality of the mushroom decreased (Kim et al., 2002; Yang et al., 2003). Some components of the softwood that are inhibitory to mycelial growth must be removed in order to utilize the softwood for the cultivation of $L$. edodes, and the removal method should be duly considered.

Sawdust-based cultivation at present is conducted exclusively using heat-resistant polyethylene bags, which cannot drain excess water formed by the mycelial from the cultures. The sawdust is the most popular basal ingredient used in synthetic formulations of substrate for producing L. edodes in the United States (Royse, 1997; Royse, 2001), but other basal ingredients may include straw, corncobs, or both. Starch-based supplements such as wheat bran, ricebran, millet, rye and maize may be added to the sawdust medium for the production of oak mushrooms. These supplements serve as major nutrients to optimize growth conditions (Royse, 1997; Royse, 2001).

Softwood sawdust is not used for L. edodes 
cultivation in Korean commercial mushroom farms. This study used a mix of sawdust and different nutrients as growth media for the cultivation of $L$. edodes mushroom by the mycelial growth and polyethylene bag method. This study was performed to evaluate the efficiency of using softwood as the sawdust medium for $L$. edodes cultivation, the effect of nutrient on the mycelial growth, change of carbon/nitrogen ratio in the sawdust medium and the effects of the addition of nutrients on the weight loss of the block sawdust media from spawning, the time of the first harvest, the mushroom yield, and the size of mushroom.

\section{MATERIALS and METHODS}

\subsection{Substrates and Fungal Strain}

The sawdusts of Quercus variabilis, Larix leptolepis, Pinus densiflora and Pinus koraiensis, which contained bark, were obtained from the Forest Research Institute, in Seoul, Korea. The sawdust of each species was collected in the spring of 2007 and was stored in an enclosed building until it was used. The moisture content of all air-dried sawdustwas approximately 10 $13 \%$ by weight. All the sawdust was screened to a 10 60 mesh size. Three hundred gram of the L. leptolepis, $P$. densiflora and $P$. koraiensis sawdustswere used after hot water extraction in $3 \ell$ of distilled water for $3 \mathrm{~h}$ by a soxhlet apparatus, washed and used as mushroom media. At this time, control sample was used as sawdust of $Q$. variabilis.

The strain of Lentinula edodes (Berk.) used in this study was FRI-Sanlim No. 5, a stock culture of the Forest Research Institute, Seoul, Korea. The stock culture was maintained on potato dextrose agar (PDA) medium at $4^{\circ} \mathrm{C}$. Mycelium of $L$. edodes was sub-cultured on the PDA medium for 2 weeks at $25^{\circ} \mathrm{C}$.

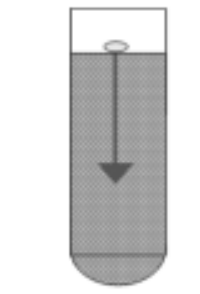

(A) Test tube incubation
(B) Petridish incubation

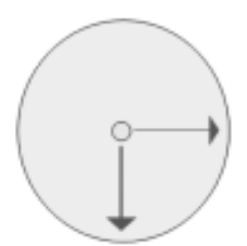

Fig. 1. Measurement method of mycelial growth in the sawdust medium. (A) Test tube : Measurement of mycelial growth length of vertical direction on the basis of inoculation surface $(\mathrm{mm})$, (B) Petridish : Measurement of mycelial growth length of horizontal direction on the basis of inoculation surface (mm).

\subsection{Determination of Nutrient on $\mathrm{My}^{-}$ celial Growth}

Sawdust medium was prepared with nutrients on the hot water extracted sawdust for the mycelial growth of $L$. edodes. Mixingrate of sawdust medium contained the following on the basis of air-dried weight (\%): sawdust, $76 \%$; rice bran, 20\%; carbon nutrition (glucose, active carbonand xylose, respectively), 3\%; nitrogen nutrition (potassium nitrate, ammonium chloride, asparagine and glutamic acid, respectively), 0.4\%; and calcium carbonate, $0.6 \%$. Vegetable oil (Sajo Haepyo Co. Korea) was applied to rice bran oil.

Prepared sawdust was packed in the test tube and petridish, and then inoculated to mycelial of L. edodes, respectively. A five mm diameter mycelial plug was cut from the margin of an actively growing fungal culture and placed fungus side down at the edge of the agar on the test tube medium and petridish medium.

Mycelial growth was measured to mycelial growth length in the two conditions (Fig. 1). Test tube was measured to mycelial growth length of vertical direction on the basis of inoculation surface, and petridish was measured to mycelial growth length of horizontal direc- 
tion on the basis of inoculation surface. And each result was the average of five replicates.

\subsection{Determination of Sawdust Medium Weight and C/N Ratio}

The weight loss of the sawdust medium was used to calculate the percentage of weight loss (1 - [weight of the sawdust medium after incubation, $\mathrm{g} /$ fresh weight of the sawdust medium before incubation, $g] \times 100$ ). The medium yield of the sawdust medium was used to calculate the percentage ([weight of the sawdust medium after incubation, g / fresh weight of the sawdust medium before incubation, g] $\times 100$ ). Subsamples of sawdust medium for analysis of elemental were oven-dried at $105^{\circ} \mathrm{C}$ for $24 \sim 48 \mathrm{~h}$ and were ground in a Wiley Mill to pass a 40 mesh screen. Total elemental composition of samples was analyzed by CHNS-932 Analyzer (Leco).

\subsection{Preparation of Sawdust Block Me- dium for Mushroom}

Three hundred grams of the resulting sawdust mixture werebagged in a polypropylene bag with a hole $4 \mathrm{~cm}$ in diameter covered with a $0.44 \mu \mathrm{m}$ filter and closed with a plastic cap with an additional $0.44 \mu \mathrm{m}$ paper filter.

The sawdusts medium were formed into blocks of $300 \mathrm{~g}$ in the polypropylene bag by a square mold $(150 \mathrm{~W} \times 60 \mathrm{~L} \times 100 \mathrm{H} \mathrm{mm})$. The apparent gravities of the sawdust medium bagged were 0.96 of $Q$. variabilis, 0.75 of $L$. leptolepis, 0.70 of $P$. densiflora and 0.67 of P. koraiensis.

Experiments were conducted in a completely randomized design with ten treatments and seven replicates. The sawdust medium in the polypropylene bags were sterilized at $121^{\circ} \mathrm{C}$ for 90 minutes, and then cooled to $25^{\circ} \mathrm{C}$. Sawdust medium in the test tube and petridish was inoculated on with four mycelial plugs (diameter $10 \mathrm{~mm}$ ) from the PDA medium with mycelial of $L$. edodes.

\subsection{Determination of Nutrient Com- position in Sawdust Block Me- dium Cultivation}

The block medium was adjusted to about 65 $\pm 2 \%$ based on the fresh weight of the mixture of solid materials with nutrients $(300 \mathrm{~g})$. The block medium was made to a block of $300 \mathrm{~g}$ in the polypropylene bag by a square mold $(150 \mathrm{~W}$ $\times 60 \mathrm{~L} \times 100 \mathrm{H} \mathrm{mm}$ ).

Carbon nutrition 3\%, nitrogen nutrition $0.4 \%$ and supplement $0.05 \%$ were added on the basis of air-dried weight of sawdust $80 \%$ and rice bran $20 \%$ (Table 1).

\subsection{Spawn Run, Cultivation and Har- vesting Mushroom}

Valuation of spawn run (mycelial growth) from the block medium was measured bytheir weight loss. The block medium were incubated at $24 \pm 2^{\circ} \mathrm{C}$ for 80 days in the dark, and then they were transferred to $24 \pm 2^{\circ} \mathrm{C}$ for 40 days in the light. At the end of dark and light incubation, the weight of the block media were used to calculate the percentage of weight loss (1 - [weight of the block medium after incubation, $\mathrm{g} /$ fresh weight of the block medium before incubation, g] $\times 100$ ). After incubation for 120 days, all block medium were taken out of the polypropylene bags, washed with tap water to induce fruiting, and soaked in cool water (13 \pm $2^{\circ} \mathrm{C}$ ) for $24 \mathrm{~h}$. The block medium was incubated for fruiting bodies in chamber (Ilshin Lab Co., $\mathrm{CC} 0150$, Korea) at $15 \sim 18^{\circ} \mathrm{C}$ and $90 \sim 98 \%$ relative humidity until fruiting bodies developed. The room was ventilated with fresh air moving at $2 \mathrm{~m} / \mathrm{s}$ and illuminated $9 \sim 12 \mathrm{~h} /$ day. This experiment was performed by the method shown in Fig. 2. 
Ji Young Jung, Seong-Cheol Hong, Danny Lee Rinker, Myung Suk Choi, Byung Hyun Lee, and Jae-Kyung Yang

Table 1. Preparation of sawdust medium for $L$. edodes based on the different nutrient content

\begin{tabular}{ccccc}
\hline \multirow{2}{*}{ Group } & \multirow{2}{*}{ Species of sawdust } & \multicolumn{3}{c}{ Content of block medium } \\
\cline { 3 - 5 } & & Carbon source & Nitrogen source & Supplement \\
\hline \hline \multirow{2}{*}{ A } & Larix leptolepis & Sucrose & Potassium nitrate & - \\
& Pinus densiflora & Sucrose & Potassium nitrate & - \\
& Pinus koraiensis & Sucrose & Potassium nitrate & - \\
\hline \multirow{2}{*}{ B } & Larix leptolepis & Glucose & Glutamic acid & - \\
& Pinus densiflora & Active carbon & Asparagine & - \\
& Pinus koraiensis & Xylose & Glutamic acid & - \\
\hline \multirow{2}{*}{ C } & Larix leptolepis & Glucose & Glutamic acid & Amino acid \\
& Pinus densiflora & Active carbon & Asparagine & Amino acid \\
& Pinus koraiensis & Xylose & Glutamic acid & Amino acid \\
\hline \multirow{2}{*}{ Control } & Quercus variabilis & Sucrose & Potassium nitrate & - \\
\hline
\end{tabular}
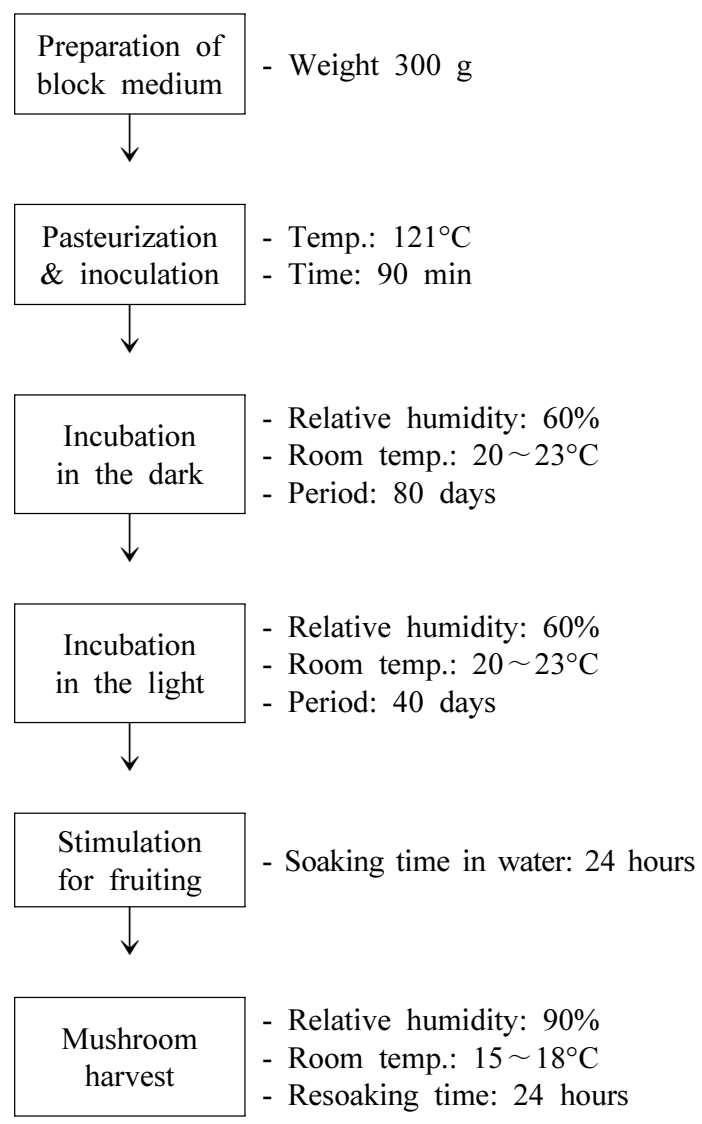

Fig. 2. Scheme of mushroom cultivation on sawdust medium in polypropylene bags for $L$. edodes.
The L. edodes mushrooms were harvested from the block medium at same time each day when in-rolled $80 \sim 90 \%$ of fruiting body gills began to flatten. The block medium clinging to the stipe werecut away and then the fresh mushrooms harvested at maturity were weighed, and the size of the cap and stipe of the mushrooms were measured. The diameter and thickness of the cap, and the length and diameter of the stipe from produced fresh fruiting bodies of the mushrooms were measured for the estimation of the mushroom quality. Seven replicateswere used for the mushroom product from each block medium. The data concerning spawn running were recorded after complete colonization of the block medium. The fresh mushroom yield was $\mathrm{g}$ fresh mushrooms harvested at maturity per $\mathrm{g}$ fresh block medium before incubation and expressed as a percentage.

\subsection{Statistics of Data}

Data was transformed to arcsin of square root of the value and analyzed using Proc Glm of SAS (Statistical Analysis System, ver.6.12). Means were separated using Duncan's new multiple range test at the $\mathrm{P}<0.05$. 
Table 2. Influence of nitrogen nutrition in the weight loss of sawdust medium

\begin{tabular}{lcccc}
\hline \multirow{2}{*}{ Species } & \multicolumn{4}{c}{ Weight loss of sawdust medium (\%) } \\
\cline { 2 - 6 } & $\begin{array}{c}\text { Potassium Ammonium } \\
\text { nitrate }\end{array}$ & chloride & Asparagine & $\begin{array}{c}\text { Glutamic } \\
\text { acid }\end{array}$ \\
\hline \hline L. leptolepis & $6.68 \mathrm{a} *$ & $6.26 \mathrm{a}$ & $6.67 \mathrm{a}$ & $6.77 \mathrm{a}$ \\
P. densiflora & $6.23 \mathrm{a}$ & $5.52 \mathrm{~b}$ & $6.74 \mathrm{a}$ & $6.39 \mathrm{a}$ \\
P. koraiensis & $5.42 \mathrm{a}$ & $4.78 \mathrm{~b}$ & $5.41 \mathrm{a}$ & $5.71 \mathrm{a}$ \\
\hline
\end{tabular}

* Means followed by the same letters within each columnare not significantly different by Ducan's multiple range test $(P>0.01$ in the L. leptolepis, $P=0.01$ in the $P$. densiflora, $P<0.01$ in the $P$. koraiensis)

\section{RESULTS and DISCUSSION}

\subsection{Effect of Nutrient on the Mycelial Growth}

All of the tested nitrogen nutritions significantly enhanced the mycelial growth of L. edodes $(P>0.01$ in the L. leptolepis, $P=$ 0.01 in the $P$. densiflora, $P<0.01$ in the $P$. koraiensis) and glutamic acid in the L. leptolepis and $P$. koraiensis, asparagine in the $P$. densiflora were appeared to slight increase in the mycelial growth (Table 2).

Fig. 3 showedthe mycelial growth following the addition of vegetable oil in the L. leptolepis, $P$. densiflora and $P$. koraiensis sawdust medium. Mycelial growth in the L. leptolepis and P. densiflora sawdust medium was decreased in the mycelial growth of addition after than before. However mycelial growth in the $P$. koraiensis sawdust medium was somewhat increased. Mycelial growth length was calculated after 11 days incubation at the $25^{\circ} \mathrm{C}$.

\subsection{Change of Carbon/Nitrogen Ratio in the Sawdust Medium}

Earlier work showed the mycelial growth effects on the carbon/nitrogen ratios (Jonathan

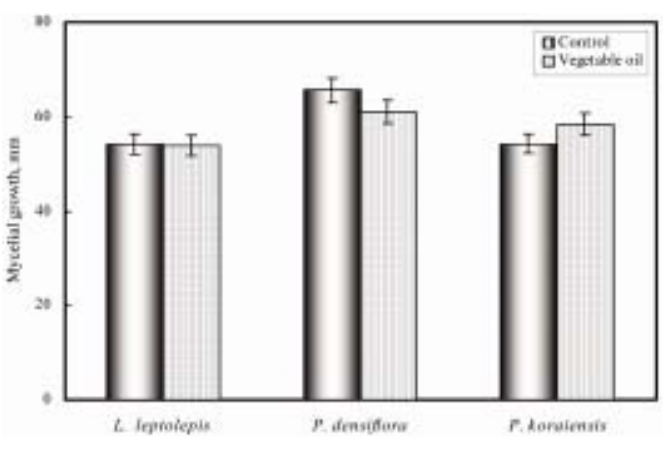

Fig. 3. Effect of vegetable oil for mycelial growth of $L$. edodesin the softwood sawdust medium of L. leptolepis, $P$. densiflora and $P$. koraiensis $\left(11\right.$ days incubation at the $\left.25^{\circ} \mathrm{C}\right)$.

and Fasidi, 2001; Fasidi and Olorunmaiye, 1994; Chandra and Purkayastha, 1997). Jonathan et al. reported the fungus grew best on a medium with ratio 2:3 followed by $3: 4$ while the least growth was obtained with the ratio 5:1 (Jonathan and Fasidi, 2001).

Table 3 showed the change of element content and carbon/nitrogen ratio. Analysis of element content in the softwood sawdust medium was compared before and after of incubation in the mycelial growth of L. edodes. Carbon/nitrogen ratio of all the tests were reduced after mycerial growth. This result was found that the mycelial growth was exclusively dependent on reduction of carbon. These results suggested that the mycelial nutrient of $L$. edodes utilize carbohydrates in the sawdust at the early growth stage.

\subsection{Weight Loss of Sawdust Block Medium}

The weight losses of the block medium in the polypropylene bags were measured to estimate spawn growth. The weight loss of the block media incubated in the polypropylene bags at the $80^{\text {th }}$ day in the dark and $120^{\text {th }}$ day in the light after inoculations wereshown in Table 4. 
Ji Young Jung, Seong-Cheol Hong, Danny Lee Rinker, Myung Suk Choi, Byung Hyun Lee, and Jae-Kyung Yang

Table 3. Changes of element composition and carbon/nitrogen ratio in the sawdust medium

\begin{tabular}{|c|c|c|c|c|c|c|c|c|}
\hline \multirow{2}{*}{ Species } & \multirow{2}{*}{$\begin{array}{l}\text { Carbon } \\
\text { nutrition }\end{array}$} & \multirow{2}{*}{$\begin{array}{l}\text { Fungi } \\
\text { growth }\end{array}$} & \multirow{2}{*}{$\begin{array}{l}\text { Medium } \\
\text { yield }^{\text {a) }} \%\end{array}$} & \multicolumn{4}{|c|}{ Element, \% } & \multirow{2}{*}{$\begin{array}{l}\mathrm{C} / \mathrm{N} \\
\text { ratio }\end{array}$} \\
\hline & & & & $\mathrm{C}$ & $\mathrm{H}$ & $\mathrm{N}$ & $\mathrm{O}$ & \\
\hline \multirow{2}{*}{ L. leptolepis } & \multirow{2}{*}{ Glucose } & Before & 100.0 & 44.5 & 4.5 & 0.7 & 49.3 & 65.0 \\
\hline & & After & 84.9 & 37.8 & 3.6 & 0.7 & 42.8 & 54.0 \\
\hline \multirow{2}{*}{ P. densiflora } & \multirow{2}{*}{$\begin{array}{l}\text { Active } \\
\text { carbon }\end{array}$} & Before & 100.0 & 47.6 & 4.5 & 0.6 & 47.3 & 79.3 \\
\hline & & After & 85.8 & 38.1 & 3.7 & 0.6 & 43.4 & 63.5 \\
\hline \multirow{2}{*}{ P. koraiensis } & \multirow{2}{*}{ Xylose } & Before & 100.0 & 45.4 & 4.7 & 0.7 & 49.2 & 64.9 \\
\hline & & After & 84.3 & 38.1 & 3.6 & 0.7 & 41.9 & 54.4 \\
\hline
\end{tabular}

a) Yield, based on the dry weight of sawdust medium

Table 4. Weight loss of block medium during incubation of the dark and light

\begin{tabular}{|c|c|c|c|}
\hline \multirow{2}{*}{ Group $^{\text {a) }}$} & \multirow{2}{*}{ Species } & \multicolumn{2}{|c|}{ Weight loss of sawdust block medium ${ }^{\mathrm{b})}, \%$} \\
\hline & & Incubation in the dark ${ }^{\mathrm{c})}$ & Incubation in the light ${ }^{\mathrm{d})}$ \\
\hline \multirow{3}{*}{ A } & L. leptolepis & $15.0 \pm 2.94 \mathrm{a} *$ & $23.2 \pm 2.99 \mathrm{abc}$ \\
\hline & P. densiflora & $14.8 \pm 2.37 \mathrm{a}$ & $21.7 \pm 2.18 \mathrm{abc}$ \\
\hline & P. koraiensis & $13.9 \pm 1.63 \mathrm{a}$ & $20.7 \pm 1.72 \mathrm{c}$ \\
\hline \multirow{3}{*}{$\mathrm{B}$} & L. leptolepis & $15.1 \pm 2.67 \mathrm{a}$ & $23.4 \pm 2.64 \mathrm{abc}$ \\
\hline & P. densiflora & $16.6 \pm 2.89 \mathrm{a}$ & $25.8 \pm 3.12 \mathrm{a}$ \\
\hline & P. koraiensis & $13.8 \pm 2.28 \mathrm{a}$ & $21.2 \pm 2.51 \mathrm{bc}$ \\
\hline \multirow{3}{*}{$\mathrm{C}$} & L. leptolepis & $15.5 \pm 2.83 \mathrm{a}$ & $24.1 \pm 1.93 \mathrm{abc}$ \\
\hline & P. densiflora & $16.8 \pm 3.01 \mathrm{a}$ & $25.3 \pm 2.05 \mathrm{ab}$ \\
\hline & P. koraiensis & $13.8 \pm 2.82 \mathrm{a}$ & $22.4 \pm 2.38 \mathrm{abc}$ \\
\hline Control & Q. variabilis & $16.8 \pm 1.66^{\mathrm{e})} \mathrm{a}$ & $25.7 \pm 1.96 \mathrm{a}$ \\
\hline
\end{tabular}

Note: See Table 1 (Nutrients of control, A, B and C groups: sawdust $80 \%+$ rice bran $20 \%+$ carbon source $3 \%+$ nitrogen source $0.4 \%+$ calcium carbonate $0.6 \%+$ amino acid $0.05 \%$ )

a) Group divided according to nutrient content of block media.

b) Moisture content of the block medium was adjusted to about $65 \pm 2 \%$ based on the fresh weight of the mixture of solid materials with nutrients $(300 \mathrm{~g})$. The block medium was made from a block of $300 \mathrm{~g}$ in the polypropylene bag by a square mold $(150 \mathrm{~W} \times 60 \mathrm{~L} \times 100 \mathrm{H} \mathrm{mm})$.

c) Media were incubated for 80 days in the dark.

d) Media were incubated for 40 days in the light after in the dark incubation.

e) Values are mean \pm S.D.(g) of seven separate experiments.

* Mean values followed by the same letter within the same column are not significantly different at the $5 \%$ level according to Duncan's New Multiple-Range Test.

In the polypropylene bag cultivation, the weight losses of the block mediumgradually increased for the 80 days in the dark (13.8 $16.8 \%$ ) and then became stable in the range of
$20.7 \sim 25.8 \%$. On the $80^{\text {th }}$ day, the percentages of the weight losses for spawn growth of $L$. edodes were not significantly different in the dark incubation, nor was there a significant differ- 
Effects of Nutrient Composition on Yield and Quality of Mushroom in Lentinula edodes Cultivation Using Softwood Sawdust

Table 5. First harvest day and yield of fruiting body according to sawdust block medium

\begin{tabular}{cccc}
\hline Group $^{\mathrm{a})}$ & Species & First harvest, days $^{\mathrm{b})}$ & Yield $^{\mathrm{c}}, \%$ \\
\hline \hline \multirow{3}{*}{$\mathrm{A}$} & L. leptolepis & $143.6 \pm 2.8 \mathrm{~d}{ }^{*}$ & $22.8 \pm 2.3 \mathrm{de}$ \\
& $P$. densiflora & $143.2 \pm 3.9 \mathrm{~d}$ & $20.5 \pm 1.3 \mathrm{ef}$ \\
& $P$. koraiensis & $151.4 \pm 6.0 \mathrm{c}$ & $19.0 \pm 1.3 \mathrm{f}$ \\
\hline \multirow{3}{*}{ B } & L. leptolepis & $139.5 \pm 1.2 \mathrm{~d}$ & $24.7 \pm 1.4 \mathrm{~cd}$ \\
& $P$. densiflora & $169.4 \pm 1.7 \mathrm{a}$ & $32.7 \pm 2.2 \mathrm{a}$ \\
& $P$. koraiensis & $138.6 \pm 1.0 \mathrm{~d}$ & $17.2 \pm 1.2 \mathrm{f}$ \\
\hline \multirow{2}{*}{ C } & L. leptolepis & $140.7 \pm 5.6 \mathrm{~d}$ & $25.9 \pm 2.2 \mathrm{~cd}$ \\
& $P$. densiflora & $169.9 \pm 3.1 \mathrm{a}$ & $27.7 \pm 2.9 \mathrm{c}$ \\
& $P$. koraiensis & $141.8 \pm 4.6 \mathrm{~d}$ & $31.5 \pm 2.5 \mathrm{~b}$ \\
\hline Control & Q. variabilis & $162.9 \pm 2.73^{\mathrm{d})} \mathrm{b}$ & $35.4 \pm 3.6 \mathrm{a}$
\end{tabular}

Note: See Table 1 (Nutrients of control, A, B and C groups: sawdust $80 \%+$ rice bran $20 \%+$ carbon source $3 \%+$ nitrogen source $0.4 \%+$ calcium carbonate $0.6 \%+$ amino acid $0.05 \%$ )

a) Group divided according to nutrient content of blockmedia.

b) Mushrooms were harvested from the block medium at the same time each day when in-rolled $80 \sim 90 \%$ offruiting body gills began to flatten.

c) Yield, $\%=$ ratio of $\mathrm{g}$ fresh mushrooms harvested at maturity per $\mathrm{g}$ fresh block media before incubation. Media were incubated for 80 days in the dark.

d) Values are mean \pm S.D.(g) of seven separate experiments.

* Mean values followed by the same letter with in the same column are not significantly different at the $5 \%$ level according to Duncan's New Multiple-Range Test.

ence between medium with different species of sawdust.

The $P$. densiflora sawdust medium in the light incubation of the $\mathrm{B}$ group had the highest weight loss $(25.8 \%)$, followed by the $Q$. variabilis sawdust medium (25.7\%) and the $P$. densiflora sawdust medium of the C group (25.3\%). These results suggested that the nutrients of the $\mathrm{B}$ group and $\mathrm{C}$ group added to the $P$. densiflora sawdust medium were effective for $L$. edodes spawn growth. After 120 day the incubation in the dark and light, the weight loss of block medium in the $\mathrm{A}, \mathrm{B}$ and $\mathrm{C}$ groups was greater than $81 \%$ of the $Q$. variabilis sawdust that was the control.

\subsection{Effect of Nutrient Composition in Sawdust Block Medium Cultivation}

After having inoculated the mycelium of $L$. edodes on the block medium, the $P$. densiflora sawdust of the B and C groups were the slowest of their respective groups on day 169.4 and day 169.9 harvesting times. The first harvest of the fruiting body from the $Q$. variabilis sawdust of the control medium was obtained on day 162.9 (Table 5).

The mushroom yield of the $P$. densiflora sawdust medium $(32.7 \%)$ in the B group was the best in mushroom production of $L$. edodes, followed by the $Q$. variabilis sawdust $(35.4 \%)$ of the control medium. The mushroom yields of the L. leptolepis (22.8\%) and P. densiflora (20.5\%) media each increased about $2 \%$ in the A group and $12 \%$ in the B group, respectively. 
Ji Young Jung, Seong-Cheol Hong, Danny Lee Rinker, Myung Suk Choi, Byung Hyun Lee, and Jae-Kyung Yang

Table 6. Measurement of mushroom size for the quality of $L$. edodes

\begin{tabular}{|c|c|c|c|c|c|}
\hline \multirow{3}{*}{ Group $^{a}$} & \multirow{3}{*}{ Species } & \multicolumn{4}{|c|}{ Mushroom size ${ }^{\text {b) }}$} \\
\hline & & \multicolumn{2}{|c|}{ Cap } & \multicolumn{2}{|c|}{ Stipe } \\
\hline & & Diameter, mm & Thickness, mm & Diameter, mm & Length, mm \\
\hline \multirow{3}{*}{ A } & L. leptolepis & $67.3 \pm 1.5 b^{*}$ & $16.6 \pm 0.5 \mathrm{ab}$ & $10.9 \pm 1.7 \mathrm{~b}$ & $27.9 \pm 2.5 \mathrm{de}$ \\
\hline & P. densiflora & $71.5 \pm 2.6 \mathrm{a}$ & $15.4 \pm 1.3 \mathrm{ab}$ & $9.0 \pm 1.2 \mathrm{bc}$ & $28.8 \pm 2.7 \mathrm{~cd}$ \\
\hline & P. koraiensis & $71.5 \pm 1.7 \mathrm{a}$ & $16.9 \pm 0.7 \mathrm{a}$ & $15.3 \pm 6.5 \mathrm{a}$ & $27.3 \pm 3.3 \mathrm{de}$ \\
\hline \multirow{3}{*}{ B } & L. leptolepis & $60.0 \pm 1.8 \mathrm{e}$ & $15.1 \pm 1.3 \mathrm{~b}$ & $7.9 \pm 0.8 \mathrm{bc}$ & $25.2 \pm 0.7 \mathrm{ef}$ \\
\hline & P. densiflora & $60.3 \pm 0.8 \mathrm{e}$ & $16.3 \pm 1.0 \mathrm{ab}$ & $9.5 \pm 0.3 \mathrm{bc}$ & $28.6 \pm 1.2 \mathrm{de}$ \\
\hline & P. koraiensis & $48.3 \pm 3.5 \mathrm{f}$ & $12.2 \pm 1.1 \mathrm{c}$ & $7.5 \pm 1.1 \mathrm{~b}$ & $22.3 \pm 1.4 \mathrm{f}$ \\
\hline \multirow{3}{*}{$\mathrm{C}$} & L. leptolepis & $61.8 \pm 3.4 \mathrm{de}$ & $15.3 \pm 1.1 \mathrm{ab}$ & $8.8 \pm 1.2 \mathrm{bc}$ & $28.3 \pm 4.8 \mathrm{de}$ \\
\hline & P. densiflora & $68.9 \pm 4.8 \mathrm{ab}$ & $16.9 \pm 2.1 \mathrm{a}$ & $8.8 \pm 0.8 \mathrm{bc}$ & $31.7 \pm 1.4 \mathrm{bc}$ \\
\hline & P. koraiensis & $72.1 \pm 1.76 \mathrm{a}$ & $15.7 \pm 1.1 \mathrm{ab}$ & $10.6 \pm 0.5 \mathrm{bc}$ & $36.3 \pm 2.9 \mathrm{a}$ \\
\hline Control & Q. variabilis & $64.4 \pm 2.3^{\mathrm{c})} \mathrm{cd}$ & $15.8 \pm 0.3 \mathrm{ab}$ & $8.6 \pm 0.2 b c$ & $32.6 \pm 0.5 \mathrm{~b}$ \\
\hline
\end{tabular}

Note: See Table 1 (Nutrients of control, A, B and C groups: sawdust $80 \%+$ rice bran $20 \%+$ carbon source $3 \%+$ nitrogen source $0.4 \%+$ calcium carbonate $0.6 \%+$ amino acid $0.05 \%$ )

a) Group divided according to nutrient content of block media.

b) Diameter and thickness of the cap and length and diameter of the stipe from produced fresh fruiting bodies were measured by digimatic caliper $(\mathrm{mm})$.

c) Values are mean \pm S.D.(g) of seven separate experiments.

* Mean values followed by the same letter within the same column are not significantly different at the $5 \%$ level according to Duncan's New Multiple-Range Test.

However, the yield of the $P$. koraiensis medium in the A group decreased about $2 \%$ in the B group, but increased about $12 \%$ in the $\mathrm{C}$ group. The first harvesting time of mushrooms from the $P$. densiflora sawdust of the B group happened on day 169.4 , but from the $P$. densiflora sawdust of the B group was obtained the cumulative yield of $32.7 \%$. The mushroom yield of the $P$. densiflora sawdust medium in the $\mathrm{C}$ group $(27.7 \%)$ with $0.05 \%$ amino acid was decreased.

For the cumulative yields during 150 days of spawning, there was a statistically significant difference among $L$. leptolepis, P. densiflora and $P$. koraiensis sawdust medium. However, there was not a significantly difference between the yields of the L. leptolepis sawdust in the B group $(24.7 \%)$ and the L. leptolepis sawdust in the C group (25.9\%), and also, there was not a significant difference between the yields of the P. koraiensis sawdust in the A $(19.0 \%)$ and B $(17.2 \%)$ groups. There was a significant difference between the yields of the $P$. koraiensis sawdust in the A, B groups and the $P$. koraiensis sawdust in the $\mathrm{C}$ group (31.5\%). The yield of the $P$. densiflora sawdust in the C group (27.7\%) with $0.05 \%$ amino acid was decreased contrary to the expectation.

The mushroom yields in all block medium of the $\mathrm{C}$ group were higher than that of the $\mathrm{A}$ group. Significant sources of variation in the analysis of variance for the yields for groups A, $\mathrm{B}$ and $\mathrm{C}$ included the sawdust species, nutrients and supplement. The best results for the diameter of mushroom cap were obtained from the $P$. densiflora sawdust and $P$. koraiensis sawdust of the A group, and the P. koraiensis sawdust of the $\mathrm{C}$ group. The values obtained were $71.5 \mathrm{~mm}$, 
$71.5 \mathrm{~mm}$ and $72.1 \mathrm{~mm}$, respectively. These were significant difference between any of the other groups and the control medium (Table 6).

The thickness of the mushroom cap of the $P$. koraiensis sawdust of the B group was the lowest at $12.2 \mathrm{~mm}$, but that of the P. koraiensis sawdust in the A $(16.9 \mathrm{~mm})$ and $\mathrm{C}(15.7 \mathrm{~mm})$ groups were thicker, than the $P$. koraiensis sawdust of the B group. There was no significant difference between the thickness of the mushroom cap of the other block medium and that of the control medium. P. koraiensis $(15.3 \mathrm{~mm})$ of the A group gave the widest diameter of stipe but the diameters of the other stipes were not significantly different from that of the control medium $(8.6 \mathrm{~mm})$. The stipe length of all block mediumin the $\mathrm{A}, \mathrm{B}$ and $\mathrm{C}$ group obtained various values. Regarding the mushroom quality from P. koraiensis of the B group, the diameter and thickness of the cap and the diameter and length of the stipe were $48.3 \mathrm{~mm}, 12.2 \mathrm{~mm}, 7.5$ $\mathrm{mm}$ and $22.3 \mathrm{~mm}$, respectively, while the corresponding values of the $\mathrm{C}$ group were $72.1 \mathrm{~mm}$ $15.7 \mathrm{~mm}, 10.6$ and $36.3 \mathrm{~mm}$, respectively. In all block medium, P. koraiensis of the B group grew the shortest length of stipe at $22.3 \mathrm{~mm}$, and $P$. koraiensis of the $\mathrm{C}$ group grew the longest length of stipe at $36.3 \mathrm{~mm}$. Comparing the $\mathrm{B}$ and $\mathrm{C}$ groups, the mushroom quality from the block medium of the $\mathrm{C}$ group with $0.05 \%$ amino acid improved. Especially, the mushroom quality of $P$. koraiensis medium in the B group improved by adding $0.05 \%$ amino acid.

\section{CONCLUSION}

In this study, softwood sawdusts of L. leptolepis, P. densiflora and P. koraiensis which the inhibitory compound for $L$. edodes were removed studied for the possible utilization in the cultivation of $L$. edodes mushroom and investigated the effect that nutrients and supplements had on the yield and quality of mushroom grown on block medium in polypropylene bags.

Nitrogen nutrition significantly enhanced the mycelial gro wth of $L$. edodes and glutamic acid in the L. leptolepis and P. koraiensis, asparagine in the $P$. densiflora were appeared to slight increase in the mycelial growth.

Mycelial growth was exclusively dependent on reduction of carbon. These results suggested that the mycelial nutrient of L. edodes utilize carbohydrates in the sawdust at the early growth stage.

The first harvest period of mushrooms grown on the $P$. densiflora medium (carbon source: $3 \%$ active carbon, nitrogen source: $0.4 \%$ asparagines) and $P$. densiflora medium (carbon source: 3\% xylose, nitrogen source: $0.4 \%$ glutamic acid) were the slowest at about 169 days, the same day that the mushroom grown on the $Q$. variabilis control medium (carbon source: 3\% sucrose, nitrogen source: $0.4 \%$ potassium nitrate) was obtained. There was no observable relationship between the first harvest period and the yield of mushroom. However, except the P. koraiensis medium (carbon source: 3\% xylose, nitrogen source: $0.4 \%$ glutamic acid), the mushroom yields produced on the nutrients of the $\mathrm{B}$ (glucose, active carbon, xylose, glutamic acid, and asparagines) and C (glucose, active carbon, xylose, glutamic acid, asparagines, and amino acid) groups were higher than that cultivated on the nutrients of the A (sucrose, potassium nitrate) group.

The diameter and thickness of the mushroom cap produced from the A (sucrose, and potassium nitrate) group were better than that of the B (glucose, active carbon, xylose, glutamic acid, and asparagines) and $\mathrm{C}$ (glucose, active carbon, xylose, glutamic acid, asparagines, and amino acid) groups. However, in comparison of the $\mathrm{B}$ (glucose, active carbon, xylose, glutamic acid, and asparagines) and the $\mathrm{C}$ (glucose, active carbon, xylose, glutamic acid, asparagines, and 
amino acid) groups, the mushroom quality produced on the block medium with $0.05 \%$ amino acid of the $\mathrm{C}$ (glucose, active carbon, xylose, glutamic acid, asparagines, and amino acid) group was higher than that of the block medium of the B (glucose, active carbon, xylose, glutamic acid, and asparagines) group.

Q. variabilis medium (carbon source: $3 \%$ sucrose, nitrogen source: $0.4 \%$ potassium nitrate) and $P$. densiflora medium (carbon source: 3\% active carbon, nitrogen source: $0.4 \%$ asparagines) and $P$. densiflora medium (carbon source: $3 \%$ xylose, nitrogen source: $0.4 \%$ glutamic acid) in dark incubation showed the highest weight loss at $16.8 \%, 16.6 \%$ and $16.8 \%$ and also, these medium showed the highest weight loss at $25.7 \%, 25.8 \%$ and $25.3 \%$ in light incubation, respectively. The results of the weight loss on the block medium in the polypropylene bags were not significantly different between the different nutrients of $\mathrm{A}, \mathrm{B}$ and $\mathrm{C}$ groups.

Softwood sawdust was practicable as a block medium for production of the L. edodes mushroom. This study demonstrated that the substrates containing carbon sources (glucose, active carbon, and xylose) and nitrogen sources (glutamic acid, and asparagine) were more productive than the substrates containing sucrose as a carbon source and potassium nitrate as a nitrogen source and that the substrates with $0.05 \%$ amino acid to the sawdust medium of L. leptolepis and P. koraiensis were more productive than the substrates without additional amino acid.

\section{REFERENCES}

1. Breene W. M. 1990. Nutritional and medicinal value of specialty mushrooms. J. Food Protect, 53: $883 \sim 894$.

2. Chandra, A. and R. P. Purkayastha. 1977. Physiological studies on Indian mushrooms. trans. Br. Mycol. Soc., 69: 6370.
3. Fasidi, I. O. and S. K. Olorunmaiye. 1994. Studies on the requirements for vegetative growth of Pleurotus tuber-regium (fr) Singer, a Nigerian mushroom. Food Chemistry, 50: $397 \sim 401$.

4. Jong, S. C. and J. M. Nirmingham. 1993. Medicinal and therapeutic value of the Shiitake mushroom. Adv. Appl. Microbiol., 39: 153 184.

5. Jonathan, S. G. and I. O. Fasidi. 2001. Effect of carbon, nitrogen and mineral sources on growth of Psathyerella atroumbonata (Pegler), a Nigerian edible mushroom. Food Chemistry, 72: 479 483.

6. Kuo, D. D. and M. H. Kuo. 1983. How to grow forest mushroom (Shitake). The Te Mushroom Technology Corp., Napervile, Illinois, pp. 95 108.

7. Kim, T. H., B. K. Lim, J. P. Chang, K. H. Yoon, J. Y. Lee, and J. K. Yang. 2002. Pretreatment of softwood sawdust for mycerial growth of Lentinus edodes. Mokchae Konghak 30(3): 109 115.

8. Luo, L. H. 1989. Cultivation of Auricularia on logs in China. In: Chang, S. T., Quimio, T. H. (Eds.), Tropical Mushrooms, Biological Nature and Cultivation Methods. The Chinese University press of Hon Kong, pp. 437 441.

9. Miles, G. P. and S. T. Chang. 1997. Mushroom Biology, Concise Basic and Current Developments. World Scientific Publishing Co., London, pp. $130 \sim 140$.

10. Quimio, T. H., S. T. Chang, and D. J. Royse. 1990. Technical guidelines for mushroom growing in the tropics. FAO plant production and protection paper 106, FAO, Rome, pp. 73 $\sim 80$.

11. Royse, D. J. 1997. Specialty mushrooms and theircultivation. Hort. Rev., 19: 59 97.

12. Royse, D. J. 2001. Cultivation of Shiitake on Synthetic and Natural Logs. College of Agricultural Sciences, Cooperative Extesion, Pennsylvania State University, University Park, PA, USA, p.12.

13. Singer, R. and B. Harris. 1987. Mushrooms and truffles, second ed. Koeltz scientific books, koenigsteinm, Federal Republic of Germany, pp. 350 $\sim 370$.

14. Yang, J. K., T. H. Kim, and B. K. Lim. 2003. Effect of supplement nutrition on the mycelial growth of Lentinus edodes. Mokchae Konghak 31(6): $60 \sim 66$. 